\title{
A RESPONSABILIDADE CIVIL E AS FORMAS DE INDENIZAÇÃO NOS CASOS DE VIOLÊNCIA OBSTÉTRICA PRATICADA EM HOSPITAIS PÚBLICOS
}

\section{CIVIL LIABILITY AND FORMS OF COMPENSATION IN CASES OF OBSTETRIC VIOLENCE PRACTICED IN PUBLIC HOSPITALS}

RVD

Recebido em

06.10 .2020

Aprovado em

26.11 .2020

\section{Isabella Sousa Feitosa ${ }^{1}$ \\ Karine Alves Gonçalves Mota ${ }^{2}$}

\section{RESUMO}

Este artigo tem como objetivo abordar e discutir os procedimentos jurídicos utilizados na responsabilização civil nos casos de violência obstétrica praticada em hospitais públicos. Utiliza-se de uma abordagem qualitativa para realizar a revisão bibliográfica sobre o tema e analisar os acórdãos utilizados no estudo. Sintetiza as formas que a violência pode se manifestar. Faz uma análise sobre a necessidade de resposta legislativa eficaz quanto ao tema. Estuda a caracterização da responsabilidade civil do estado e seu direito de regresso. Deduz os possíveis danos indenizáveis por meio de precedentes jurisprudenciais. Por fim, faz uma reflexão sobre as dificuldades enfrentadas pelas vítimas ao buscarem a reparação pelos danos, e sobre a forma que os acórdãos são proferidos atualmente, além de apontar a necessidade do reconhecimento da violência obstétrica como violência de gênero no ordenamento jurídico brasileiro.

Palavras-chave: direitos da parturiente; responsabilidade do estado; violência obstétrica.

\section{ABSTRACT}

This article aims to address and discuss the legal procedures used in civil accountability in cases of obstetric violence practiced in public hospitals. A qualitative approach is used to carry out the literature review on the subject and analyze the judgments used in

\footnotetext{
${ }^{1}$ Acadêmica de Direito pelo Centro Universitário Católica do Tocantins. E-mail: isabella.feitosa@a.catolica-to.edu.br. ORCID https://orcid.org/0000-0003-4364-2743

ENDEREÇO DE CONTATO: Quadra 1104 Sul, Alameda 13, n. 30, Palmas-TO

2 Doutora em ciências pela USP, Mestre em Direito pela Unimar, Graduação em Direito pela PUC de Goiás.E-MAIL: karine.mota@catolica-to.edu.br.ORCID: https://orcid.org/0000-0002-6820-470X.

ENDEREÇO DE CONTATO: Quadra 208 Sul, Alameda 15, n. 17, Palmas-TO
} 
the study. It summarizes the ways that violence can manifest itself. It analyzes the need for an effective legislative response on the subject. It studies the characterization of the state's civil liability and its right of return. It deduces the possible damages indemnified through previous jurisprudential. Finally, it thinks about the difficulties faced by victims in seeking reparation for the damage, and on the way that judgments are currently delivered, in addition to pointing out the need for recognition of obstetric violence as gender-based violence in the Brazilian legal system.

Keywords: parturient rights; responsibility of the state; obstetric violence.

\section{INTRODUÇÃO}

Violência obstétrica é um termo pouco conhecido no Brasil, mesmo que uma em cada quatro mulheres já tenha sido vítima desse tipo de agressão. A falta de informação sobre este assunto pode levar a uma série de consequências, já que muitas vítimas sabem que sofreram um tipo de abuso, mas não sabem como reagir a isso. Essa violência muitas vezes é causada pela equipe médica em geral, médicos, enfermeiros, dentre outras pessoas. Essas pessoas podem causar danos irreparáveis a essas mulheres e não há valor que mensure o sofrimento que esses danos podem causar.

Diante de uma situação dessas, muitas vítimas se perguntam como buscar ajuda jurídica para que seus direitos sejam assegurados e se depararam com a dúvida sobre a quem atribuir a responsabilidade de reparar os danos sofridos. Nos casos que essa violência ocorre em hospitais públicos, há uma dificuldade em distinguir a quem deve ser atribuída a responsabilidade, quer seja o Estado ou aos autores diretos.

Dessa forma, busca-se abordar os procedimentos jurídicos que podem ser adotados na verificação da responsabilidade civil nos casos de violência obstétrica praticada em hospitais públicos e as formas que as vítimas podem ter asseguradas a indenização, de maneira dedutiva, a fim de que se chegue a entender como são garantidos os direitos das parturientes na esfera cível, enquanto não há soluções na esfera criminal. 


\section{VIOLÊNCIA OBSTÉTRICA E SEUS ASPECTOS}

Violência obstétrica pode ser entendida como uma violência institucional decorrente da equipe médica em relação a parturiente. Uma pesquisa de opinião pública denominada "Mulheres brasileiras e gênero nos espaços público e privado" concluiu que uma em cada quatro mulheres afirma ter sofrido algum tipo de violência no ambiente de seu parto. Além disso, quando questionado sobre a rede de saúde em que ocorreu a violência, se concluiu que esses episódios aconteceram mais em hospitais públicos do que privados. (VENTURI et al., 2010).

É perceptível na cultura brasileira a preferência pela cirurgia cesariana, dado os tabus existentes relacionados ao parto natural. De acordo com a Resolução oㅡ 2.144/2016 do Conselho Federal de Medicina, é ético o médico atender à vontade da gestante de realizar parto cesariano a partir da $39^{a}$ semana de gestação, garantindo assim a segurança da parturiente e do feto, visto que o período compreendido entre a $37^{a}$ e $39^{a}$ semana é essencial para a formação do bebê.

Silva e Serra (2017) mencionam que o empoderamento feminino no quesito parto natural trouxe a parturiente como protagonista do parto, tirando um pouco de todo o crédito que o médico obstetra levava, e em razão disso o processo natural vem sendo substituído por intervenções médicas desnecessárias, como as cirurgias cesarianas, para que o médico volte a ser o protagonista do parto, podendo transformar um momento único em um traumático episódio de violência obstétrica.

Ocorrem casos em que a gestante tem preferência pelo parto natural, mas seu médico obstetra a induz a optar pela cirurgia. Muitas vezes esse induzimento ocorre no momento do trabalho de parto, no qual o médico afirma que o parto natural será inviável, e a parturiente não tem outra opção a não ser aceitar, dada a vulnerabilidade que se encontra nessas situações.

Tal conduta é reconhecida em leis estaduais, vejamos um exemplo: 
Art. 3ํㅗa efeitos da presente Lei, considerar-se-á ofensa verbal ou física, entre outras, as seguintes condutas:

V - realizar cesariana sem a devida indicação formal técnica, deixando de registrar em prontuário a indicação e não informando a paciente e familiares, salvo situações emergenciais que coloquem em risco o binômio, mãe e filho. (TOCANTINS, 2018).

A Organização Mundial da Saúde (OMS) recomenda que o índice de cirurgias cesarianas deve ser próximo de 15\%. Segundo a pesquisa Global epidemiology of use of and disparities in caesarean sections, no Brasil esse índice se aproxima de 56\%, o que coloca o país em segundo lugar no ranking mundial de cirurgias cesáreas, ficando abaixo apenas do índice da República Dominicana.

A violência obstétrica pode se manifestar de forma física, verbal, psicológica, institucional, moral e até mesmo sexual. O dossiê realizado pela rede Parto do Princípio (2012) diz que os atos caracterizadores da violência obstétrica são aqueles praticados contra a mulher em razão de sua saúde sexual e reprodutiva podendo ser praticada pelos profissionais da saúde e até mesmo técnicos administrativos de instituições públicas e privadas.

A violência em sua forma física pode acontecer quando causarem sofrimento, dor ou danos físicos ao corpo da mulher. Por exemplo: deixar de utilizar analgésicos quando necessário, não permitir que a mulher se movimente, realizar o "ponto do marido", costurando a genitália além do necessário, indicação de cirurgia cesariana desnecessária, e a manobra de Kristeller, a qual o profissional da saúde se posiciona sobre o corpo da parturiente, pressionando seu útero para facilitar a retirada do bebê.

Em sua tese, Janaina Marques de Aguiar traz um relato sobre essa manobra:

Com força. Assim, aqui doía muito, porque eles empurravam aqui (o abdômen) e, não sei, aqui não pegou anestesia. Tanto que na hora do parto, um pouquinho antes, então, aí eles me deram uma outra anestesia local porque a raqui, não sei se não fez tanto efeito. (P15 quando perguntada se alguém tinha feito força em cima de sua barriga para empurrar o neném). (AGUIAR, 2010, p. 64).

$\mathrm{Na}$ forma psicológica, os agressores causam na vítima o sentimento de inferioridade, impotência e vulnerabilidade. O agressor realiza ameaças, conta mentiras, 
faz piadas, humilha, e até desrespeita os padrões culturais da vítima. Essa forma, é considerada uma das formas mais silenciosas de manifestação, e ainda a mais difícil de ser provada muitas vezes pela falta de testemunhas, principalmente quando o direito ao acompanhante é negado.

Frases como "Na hora que você estava fazendo, você não estava gritando desse jeito, né?", "Não chora não, porque ano que vem você tá aqui de novo.", "Se você continuar com essa frescura, eu não vou te atender." e "Na hora de fazer, você gostou, né?" são frases trazidas como relatos no Dossiê Parirás com Dor, da rede Parto do Princípio (2012).

A violência sexual se manifestará toda vez que violar a intimidade ou os direitos sexuais e reprodutivos da parturiente, como por exemplo: assédio, exames de toque excessivos e invasivos, constranger a gestante a realizar a cirurgia cesariana sem seu consentimento, e episiotomia. Essa última, se caracteriza pelo corte na região do períneo, para facilitar a saída do bebê. Aguiar menciona:

Dos treze partos normais, em sete houve relatos que sugerem o uso de episiotomia, em cinco a manobra de Kristeller e em dois o uso de fórcipe. Em nenhum dos casos houve intercorrências que prejudicassem a saúde do bebê, da perspectiva das mulheres. Contudo, uma paciente, P3, queixou-se da condução de seu parto e do resultado da episiotomia: "Me costuraram todinha, rasgaram isso meu, aqui, aqui. Olha, fizeram um estrago na minha vagina!" (P3). (AGUIAR, 2010, p.64)

Também há de se falar na violência institucional, que se caracteriza por "ações ou formas de organização que dificultem, retardem ou impeçam o acesso da mulher aos seus direitos constituídos, sejam estes ações ou serviços". (PARTO DO PRINCÍPIO, 2012, p. 61). Acontece quando há o impedimento ao acesso aos serviços de saúde, ou o acesso à amamentação, violação dos direitos constitucionais da mulher, e também o desrespeito à Lei n 11.108 , conhecida como "Lei do Acompanhante".

\section{LEGISLAÇÃO SOBRE VIOLÊNCIA OBSTÉTRICA}


Países como Argentina e Venezuela já tipificaram essa conduta em seus ordenamentos jurídicos, sendo que a Venezuela foi o primeiro país latino-americano a utilizar a expressão em 2007, ao publicar a Lei Orgânica sobre o Direito das Mulheres a uma Vida Livre de Violência. Desde então, especialistas iniciaram estudos sobre a humanização do parto, para que práticas como essas sejam abolidas na prática da obstetrícia.

No Brasil, não há legislação federal específica vigente que verse sobre o tema. Porém, existem Projetos de Lei em trâmite no Congresso Nacional. São exemplos o Projeto de Lei ㄲo 7.633/2014, de autoria do ex Deputado Jean Wyllys, que dispõe sobre a humanização da assistência à mulher e ao neonato durante o ciclo gravídicopuerperal e dá outras providências, além do Projeto de Lei o 8.219/17, de autoria do deputado Francisco Floriano, que dispõe sobre a violência obstétrica praticada por médicos e/ou profissionais de saúde contra mulheres em trabalho de parto ou logo após.

Todavia, no âmbito estadual, alguns estados brasileiros como Tocantins, Santa Catarina, Minas Gerais, Paraná, Pernambuco, Goiás, Paraíba, Mato Grosso do Sul, Rondônia, Amazonas, dentre outros, já editaram leis sobre violência obstétrica de modo a visar a proteção das parturientes. Entretanto, há de se observar que a maioria das leis editadas pelos estados citados, se limitam a definir as situações caracterizadoras da violência e estabelecer que os órgãos competentes fiscalizarão e realizarão a aplicação das sanções mediante procedimento administrativo, assegurada ampla defesa.

Cabe ressaltar que essas leis estaduais, embora descrevam as condutas caracterizadoras da violência obstétrica, foram omissas ao estabelecer as possíveis sanções a serem aplicadas aos agressores, o que compromete a eficácia dessas Leis, além de estabelecer uma insegurança jurídica às vítimas dessa violência.

A Lei oㅜ 11.412, de 20 de agosto de 2019, do Estado da Paraíba estabelece em seu Artigo 11: "Os e as profissionais de saúde que praticarem atos de violência obstétrica ficam pessoalmente sujeitos à responsabilização civil e criminal decorrente de suas condutas.". De fato, é plenamente praticada a responsabilidade civil desses 
agressores, o que será estudado nos capítulos adiantes. Entretanto, no que se refere à responsabilização penal é que se nota a omissão por parte da União.

O Art. 22 da Constituição Federal de 1988 prevê expressamente que compete privativamente à União legislar sobre Direito Civil e Penal. Dessa forma, não há como exigir a tipificação dessas condutas em crime pelos Estados, que já colaboram em prever as condutas para fins de referência. Como já dito, não há legislação federal que verse sobre o assunto em âmbito penal e sequer civil. Se trata de uma afronta ao fundamento constitucional da dignidade da pessoa humana a União se omitir de tal forma, deixando essas vítimas a mercê de seus agressores.

Dessa forma, faz-se necessário que essa conduta seja reconhecida em lei federal para que se intensifique a fiscalização dessas condutas, e essa necessidade se dá uma vez que mais da metade dos estados brasileiros vêm tentando tomar providências legislando sobre, de modo que assim se passe a respeitar os direitos fundamentais da mulher e garantir a sua igualdade e dignidade diminuindo a judicialização dessas demandas em busca de reparação civil.

\section{RESPONSABILIDADE CIVIL}

\subsection{Conceito, Classificações E Elementos}

Para o Direito, responsabilidade civil é o dever de assumir as consequências jurídicas de que um fato em que se deu causa. Diferencia-se da responsabilidade moral, devido a coercitividade presente na responsabilidade civil. $\mathrm{O}$ artigo 927 do Código Civil brasileiro diz: "Aquele que, por ato ilícito (arts. 186 e 187), causar dano a outrem, fica obrigado a repará-lo." (BRASIL, 2002). Logo, conclui-se que a noção jurídica de responsabilidade necessita de uma atividade danosa de alguém que, atuando ilicitamente, viola uma norma jurídica preexistente, subordinando-se, às consequências do seu ato.

Dentre as classificações da responsabilidade civil, destaca-se a responsabilidade objetiva e a responsabilidade subjetiva. As duas se diferenciam através de um elemento 
clássico para a responsabilização: culpa. Sempre que houver culpa, ou seja, o agente der causa ao dano, sua responsabilidade será subjetiva. De acordo com Gonçalves (2019), a lei impõe a certas pessoas, em algumas situações, a reparação de um dano mesmo que não decorra de sua culpa. Nesses casos, a responsabilidade é legal ou objetiva, porque prescinde da culpa e se satisfaz apenas com o dano e o nexo de causalidade.

Conforme consta no Código Civil Brasileiro (2002), em seu artigo 186, "aquele que, por ação ou omissão voluntária, negligência ou imprudência, violar direito e causar dano a outrem, ainda que exclusivamente moral, comete ato ilícito.", é possível extrair os elementos para que haja a responsabilização civil. São eles: ação ou omissão, dolo ou culpa, nexo de causalidade e o dano sofrido pela vítima.

A ação ou omissão, se trata de quando alguém fazendo ou deixando de fazer algo, causar um dano a alguém. Do mesmo modo, é necessário que haja dolo ou culpa ao realizar a ação ou omissão. Sendo que a culpa, ocorre sempre que houver imprudência, negligência ou imperícia. Logo, "o dolo consiste na vontade de cometer uma violação de direito, e a culpa, na falta de diligência." (GONÇALVES, 2019, p. 63).

Também se faz extremamente necessário para a configuração da responsabilidade o nexo de causalidade entre a ação ou omissão e o dano causado. "Se houve o dano, mas sua causa não está relacionada com o comportamento do agente, inexiste a relação de causalidade e também a obrigação de indenizar." (GONÇALVES, 2019, p. 63). Por fim, é imprescindível a prova do dano para que alguém seja responsabilizado, e esse dano poderá ser simplesmente moral, ao invés de material, repercutindo apenas sobre a índole do ofendido.

\subsection{Responsabilidade Civil do Estado}

A Constituição Federal (1988) traz em seu artigo 196 o preceito fundamental do direito à saúde, de modo a garanti-la mediante políticas sociais e econômicas que visem à redução do risco de doença e de outros agravos e ao acesso universal e igualitário às ações e serviços para sua promoção, proteção e recuperação. 
Nesse sentido, a Constituição Federal nos diz:

Art. 37. A administração pública direta e indireta de qualquer dos Poderes da União, dos Estados, do Distrito Federal e dos Municípios obedecerá aos princípios de legalidade, impessoalidade, moralidade, publicidade e eficiência e, também, ao seguinte:

$\S 60$ As pessoas jurídicas de direito público e as de direito privado prestadoras de serviços públicos responderão pelos danos que seus agentes, nessa qualidade, causarem a terceiros, assegurado 0 direito de regresso contra o responsável nos casos de dolo ou culpa. (BRASIL, 1988, grifo nosso).

Assim, podemos entender que é obrigação do Estado prover a saúde ao seu povo, e toda e qualquer violação a esse direito é de sua responsabilidade. De acordo com a doutrina majoritária, essa responsabilidade deriva da teoria da responsabilidade sem culpa, da qual surge o dever de indenizar sem a necessidade de comprovação de culpa ou dolo do agente público que causou o dano, sendo assim a responsabilidade objetiva.

Conforme jurisprudências, é necessário a comprovação de culpa para que seja o profissional da saúde responsabilizado. Já conforme a Constituição Federal, não é necessário comprovar dolo ou culpa para que o Estado seja responsabilizado. "Assim, a responsabilidade do hospital (prestador de serviço) é objetiva, ao passo que a do médico é subjetiva." (GAGLIANO; FILHO, 2019, p. 286).

Sobre a responsabilidade objetiva do Estado em um caso de violência obstétrica ocorrido em um hospital da rede pública de saúde, vejamos:

CIVIL. PROCESSUAL CIVIL. CONSTITUCIONAL. AGRAVO RETIDO. NÃO CONHECIMENTO. AÇÃO INDENIZATÓRIA. MODIFICAÇÃO DA MODALIDADE DE PARTO, DE CESÁREA PARA PARTO NORMAL FORÇADO (À FÓRCEPS E MEDIANTE A UTILIZAÇÃO DA "MANOBRA KRISTELLER"). NASCIMENTO DE CRIANÇA COM SEQUELAS. DISTÓCIA DE OMBRO. LESÃO DO PLEXO BRAQUIAL. RESPONSABILIDADE OBJETIVA DO ESTADO. TEORIA DO RISCO ADMINISTRATIVO. PRESENÇA DOS PRESSUPOSTOS. DANO MORAL CONFIGURADO. DANO ESTÉTICO. INCLUSÃO NO CONCEITO GERAL DE DANO MORAL. QUANTUM. OBEDIÊNCIA AOS PRINCÍPIOS DA RAZOABILIDADE E DA PROPORCIONALIDADE. ADSTRIÇÃO À NORMATIVA DA EFETIVA EXTENSÃO DO DANO (CC, 
ART. 944). SENTENÇA MANTIDA. [...] 2. A TEORIA DO RISCO ADMINISTRATIVO CONSTITUI FUNDAMENTO DO ART. 37, § 60, DA CONSTITUIÇÃO FEDERAL (REFORÇADO PELOS ARTS. 43, 186 E 927 DO CC), O QUAL DISCIPLINA A RESPONSABILIDADE CIVIL OBJETIVA DO PODER PÚBLICO PELOS DANOS QUE SEUS AGENTES, NESSA QUALIDADE, CAUSAREM A TERCEIROS, RESSALVADO O DIREITO DE REGRESSIVO CONTRA O REAL CAUSADOR. BASTA, POIS, A PROVA DO FATO LESIVO, DA OCORRÊNCIA DANO E DO NEXO CAUSAL ENTRE ELES, PARA FINS DE RESPONSABILIZAÇÃO DO ESTADO, SENDO DESNECESSÁRIO PERQUIRIR ACERCA DA EXISTÊNCIA DE CULPA DO AGENTE. [...] (DISTRITO FEDERAL, 2014, grifo nosso).

Para que haja a responsabilização do estado, se faz irrelevante se o ato lesivo é lícito ou ilícito, sendo necessária apenas algum tipo de prejuízo à vítima causado pelo agente público em razão de uma ação ou omissão. Entretanto, há peculiaridades na responsabilização do Estado por sua omissão. Segundo Alexandre Mazza (2019), o entendimento doutrinário tradicional é que sempre que um dano for causado por alguma omissão, a indenização só será devida se a vítima comprovar que o prejuízo foi produzido por essa omissão.

Esse entendimento foi adotado pelo Supremo Tribunal Federal através do RE 179.147, especificando que nos casos de omissão do estado, a responsabilidade civil é subjetiva, sendo necessário demonstrar dolo ou culpa em suas modalidades negligência, imprudência ou imperícia para que se caracterize o dano indenizável.

Sobre a hipossuficiência da vítima, Alexandre Mazza (2019) nos diz que devido a vítima estar em posição de vulnerabilidade em relação ao Estado, há de se observar a inversão do ônus da prova no que se tratar de dolo ou culpa, e que quando comprovado o prejuízo presumir-se-á a responsabilidade do estado, restando a ele comprar a inexistência do dolo ou da culpa.

Segundo Gonçalves (2019), a ação deverá ser proposta no prazo prescricional de três anos, conforme alteração trazida pelo Código Civil de 2002, que unificou os prazos das ações de ressarcimento de danos. Entretanto, o Superior Tribunal de Justiça passou a sustentar a aplicação do prazo de cinco anos para ações indenizatórias propostas em face do Estado, baseando-se no Decreto 20.910/32 e 
afirmando que o Código Civil regula o direito privado, não devendo ser aplicado nas relações jurídicas de direito público.

\section{O DIREITO DE REGRESSO}

Diante das lesões sofridas pelas vítimas e a urgência na reparação do dano, surgiu o questionamento sobre a possibilidade de que a vítima ajuíze a ação em face do próprio profissional que the causou o dano, desde que comprovada a culpa e até mesmo o dolo do agente, ignorando a reponsabilidade objetiva do estado, já que se o estado entraria com ação em regresso, o resultado final seria o agente pagando pelo dano. Dessa forma decidiu o Tribunal de Justiça do Rio Grande do Sul:

RESPONSABILIDADE CIVIL. AÇÃO INDENIZATÓRIA. ATENDIMENTO EM HOSPITAL PÚBLICO. LEGITIMIDADE PASSIVA DO MÉDICO. RESPONSABILIDADE SUBJETIVA. NECESSIDADE DE COMPROVAÇÃO DA CULPA. Caso em que o autor reclama por danos morais sofridos em razão de suposto mau atendimento oferecido por médicos em centro de saúde desta Capital. Legitimidade passiva dos médicos. Faculdade que possui a parte de ajuizar ação contra 0 profissional de saúde e/ou o ente Público/Hospital. Precedentes jurisprudenciais. Necessidade de serem observados os princípios do contraditório, ampla defesa e duplo grau de jurisdição. APELAÇÃO PROVIDA. SENTENÇA DESCONSTITUÍDA. UNÂNIME. (RIO GRANDE DO SUL, 2014, grifo nosso)

Porém, diante dessas controvérsias, em 2019 o Supremo Tribunal Federal pacificou o assunto através do Tema 940, decidindo que sempre que for causado danos a terceiros por agentes públicos, a ação deverá ser proposta em face do órgão responsável pelo agente causador do dano, levando a interpretação literal do que aponta o Art. 37, § 6º da Constituição Federal.

RESPONSABILIDADE CIVIL - INDENIZAÇÃO - RÉU AGENTE PÚBLICO - ARTIGO 37, § 6, DA CONSTITUIÇÃO FEDERAL ALCANCE - ADMISSÄO NA ORIGEM - RECURSO EXTRAORDINÁRIO - PROVIMENTO. O Tribunal, por unanimidade, apreciando o tema 940 da repercussão geral, deu provimento ao recurso, nos termos do voto do Relator. Não participou, justificadamente, 
da votação de mérito, o Ministro Gilmar Mendes. Em seguida, por maioria, acolhendo proposta do Ministro Ricardo Lewandowski, fixou a seguinte tese: "A teor do disposto no art. $37, \S 6^{\circ}$, da Constituição Federal, a ação por danos causados por agente público deve ser ajuizada contra o Estado ou a pessoa jurídica de direito privado prestadora de serviço público, sendo parte ilegítima para a ação o autor do ato, assegurado 0 direito de regresso contra 0 responsável nos casos de dolo ou culpa", vencidos os Ministros Marco Aurélio, Edson Fachin e Luiz Fux. Falou, pela interessada, o Dr. Aristides Junqueira Alvarenga. Ausentes, justificadamente, os Ministros Celso de Mello e Carmen Lúcia. Presidência do Ministro Dias Toffoli. (SUPREMO TRIBUNAL FEDERAL, 2019, grifo nosso).

A própria Constituição Federal assegura o direito de regresso por parte do Estado em face do agente público que causar o dano, e a sua finalidade é verificar a reponsabilidade do agente causador do dano através de dolo ou culpa, sendo então essa responsabilidade do agente subjetiva, ao contrário da responsabilidade do Estado. Segundo o princípio administrativo da indisponibilidade, essa ação regressiva é um dever da Administração Pública.

Sobre os pressupostos da ação de regresso, Alexandre Mazza ensina:

São pressupostos para a propositura da ação regressiva:

1) condenação do Estado na ação indenizatória;

2) trânsito em julgado da decisão condenatória (não precisa aguardar o levantamento do precatório);

3) culpa ou dolo do agente;

4) ausência de denunciação da lide na ação indenizatória. (MAZZA, 2019, p. 493).

Além da doutrina majoritária, os tribunais tem decidido que não é necessária a denunciação da lide ao agente, visto a afronta ao princípio da celeridade processual, já que o processo demoraria o dobro de tempo pelo fato da necessidade de averiguar a responsabilidade subjetiva do sujeito que adentrou o processo. Assim diz o Superior Tribunal de Justiça:

RECURSO ESPECIAL. ADMINISTRATIVO. RESPONSABILIDADE CIVIL OBJETIVA DO ESTADO. MORTE DECORRENTE DE ERRO MÉDICO. DENUNCIAÇÃO À LIDE. NÃO OBRIGATORIEDADE. RECURSO DESPROVIDO. 1. Nas ações de indenização fundadas na responsabilidade civil objetiva do Estado (CF/88, art. 37, § 6)ㅡ. não é obrigatória a denunciação à lide do agente supostamente responsável 
pelo ato lesivo (CPC, art. 70, III). 2. A denunciação à lide do servidor público nos casos de indenização fundada na responsabilidade objetiva do Estado não deve ser considerada como obrigatória, pois impõe ao autor manifesto prejuízo à celeridade na prestação jurisdicional. Haveria em um mesmo processo, além da discussão sobre a responsabilidade objetiva referente à lide originária, a necessidade da verificação da responsabilidade subjetiva entre o ente público e o agente causador do dano, a qual é desnecessária e irrelevante para o eventual ressarcimento do particular. Ademais, o direito de regresso do ente público em relação ao servidor, nos casos de dolo ou culpa, é assegurado no art. $37, \S 60$, da Constituição Federal, o qual permanece inalterado ainda que inadmitida a denunciação da lide. 3. Recurso especial desprovido. (SUPERIOR TRIBUNAL DE JUSTIÇA, 2009, grifo nosso).

Assim, os três requisitos: ação ou omissão, nexo causal e dano, o estado poderá ser responsabilizado pelos danos causados por seus agentes, assegurado o direito de regresso. Esse instituto possui conexão com o princípio da dignidade da pessoa humana, e traz a prática por parte do estado desse preceito fundamental do ordenamento jurídico brasileiro. É fato que para que essa questão seja esclarecida sempre dependerá das circunstâncias do caso concreto, a depender também da natureza do dano praticado pelo agente, da intensidade.

\section{DOS DANOS INDENIZÁVEIS}

A doutrina costuma conceituar o dano como uma desvantagem que nossos bens jurídicos são submetidos, como patrimônio, corpo, honra, saúde, vida, etc. Já a indenização traz o sentido de reparação dessa desvantagem sofrida. Gonçalves (2019) afirma que indenização é um gênero do qual reparação e ressarcimentos são espécies. Essas espécies, por sua vez, diferenciam-se pelo fato de ressarcir ser uma ação de caráter patrimonial, enquanto a ação de reparar é de caráter extrapatrimonial.

Não resta dúvidas acerca das consequências que essa violência pode acarretar na vida da parturiente, e muitas vezes na do neonato. Esses danos, dependendo da sua gravidade, podem ser indenizáveis. Flávio Tartuce (2018) em seu Manual de Responsabilidade Civil enumera os danos indenizáveis existentes no Brasil, são eles: 
Danos materiais, morais, estéticos, sociais, por perda de chance ou tempo, entre outros. Cada dano se caracterizará de acordo com o caso concreto. Contudo, segundo a forma que os tribunais vêm decidindo, os danos mais comuns nos casos de violência obstétrica são materiais, morais e estéticos.

\subsection{Do Dano Moral}

Já os danos morais, são aqueles que possuem caráter extrapatrimonial, que ferem os direitos da personalidade, acarretando à pessoa lesada sofrimento, humilhação e vexame. Conforme Tartuce (2018) para a sua reparação não é necessário um preço para medir a dor ou o sofrimento, e que constitui uma forma de diminuir as consequências do prejuízo sofrido. O dano moral não tem por intenção reparar a dor ou o sofrimento da pessoa que foi lesada, mas reparar um interesse que visaria a satisfação ou gozo de um bem jurídico extrapatrimonial.

A Constituição Federal prescreve:

Art. $5^{\circ}$ Todos são iguais perante a lei, sem distinção de qualquer natureza, garantindo-se aos brasileiros e aos estrangeiros residentes no País a inviolabilidade do direito à vida, à liberdade, à igualdade, à segurança e à propriedade, nos termos seguintes:

$X$ - são invioláveis a intimidade, a vida privada, a honra e a imagem das pessoas, assegurado o direito a indenização pelo dano material ou moral decorrente de sua violação; (BRASIL, 1988, grifo nosso).

Os doutrinadores chamam atenção dizendo que se deve avaliar o que de fato é uma agressão a um direito da personalidade, logo "Mero dissabor, aborrecimento, mágoa, irritação ou sensibilidade exacerbada estão fora da órbita do dano moral." (CAVALIERI FILHO, 2020, p. 102). Para caracterizar o dano moral, é necessária uma agressão a dignidade da pessoa que se diz ofendida, um dano razoavelmente grave.

Gonçalves (2019) ensina que o dano moral, em regra, não exige prova concreta, visto que que se passa no interior da personalidade do ofendido, sendo uma presunção absoluta. Na jurisprudência mais atual, é dominante o entendimento de que é controvertida a realização de perícia psicológica a fim de constatar a dor sofrida. 
Como já mencionado, a violência obstétrica pode se manifestar de forma moral ou psicológica, sendo então plenamente possível a caracterização do dano moral visto o ataque a dignidade da parturiente em momento tão delicado. Nesse sentido, assim decidiu o Tribunal de Justiça de São Paulo:

RESPONSABILIDADE CIVIL - DANO MORAL - VIOLÊNCIA OBSTÉTRICA.

Direito ao parto humanizado é direito fundamental. Direito da apelada à assistência digna e respeitosa durante o parto que não foi observado. [...] Privação do direito à acompanhante durante todo o período de trabalho de parto. Ofensas verbais. Contato com o filho negado após o nascimento deste. Abalo psicológico in re ipsa. [...] Paciente que ficou doze horas em trabalho de parto para só então ser encaminhada a procedimento cesáreo. Apelada que teve ignorada a proporção e dimensão das suas dores. O parto não é um momento de "dor necessária". Dano moral mantido. Quantum bem fixado, em razão da dimensão do dano e das consequências advindas. Sentença mantida. Apelo improvido. (SÃO PAULO, 2017, grifo nosso);

Ressalte-se que nesta decisão foi reconhecido o parto humanizado como direito fundamental, fortalecendo o entendimento de que a violência obstétrica ofende as garantias fundamentais estabelecidas pelo Art. $5^{\circ}$ da Constituição Federal, devendo ser combatida e veemente repudiada pelos tribunais.

\subsection{Do Dano Material}

Os danos materiais ou patrimoniais são aqueles de cunho financeiro que atingem o patrimônio da vítima. Possui como objeto a efetiva diminuição do patrimônio. Sérgio Cavalieri (2020) afirma que nem sempre o dano material decorrerá da lesão a bens ou interesses patrimoniais, e que é plenamente possível que a violação a bens personalíssimos reflita no patrimônio da vítima, gerando prejuízos e despesas.

Segundo Tartuce (2018) o dano material, diferentemente do dano moral, deve ser provado por quem alega e não pode ser eventual nem presumido, devendo ser atual e certo. A indenização deverá será estipulada de acordo com a extensão do dano, ou seja, da perda patrimonial. A doutrina costuma ressaltar que quando se fala em 
danos materiais, a expressão mais correta a se utilizar é ressarcimento, apesar de não se perder o sentido quando se utiliza a expressão reparação.

A violência obstétrica em sua forma física, a depender de sua intensidade, pode levar a vítima a diversas complicações físicas. A título de exemplo, uma episiotomia mal executada pode gerar uma lesão que pode ir desde a entrada vaginal até o esfíncter. Lesão essa cuja recuperação é extremamente delicada, podendo levar a outras complicações como incontinência urinária e fecal.

Esse tipo de lesão pode chegar a levar à incapacidade laboral da vítima, podendo então caracterizar uma lesão a um direito personalíssimo que refletirá sobre o patrimônio da vítima. Para exemplificar, vejamos o acórdão proferido pelo Supremo Tribunal Federal em 2013 no caso de uma parturiente que sofreu uma lesão esfincteriana decorrente de um procedimento de episiotomia:

EMENTA: RESPONSABILIDADE CIVIL OBJETIVA DO PODER PÚBLICO - ELEMENTOS ESTRUTURAIS - PRESSUPOSTOS LEGITIMADORES DA INCIDÊNCIA DO ART. 37, § 60, DA CONSTITUIÇÃO DA REPÚBLICA - TEORIA DO RISCO ADMINISTRATIVO - HOSPITAL PÚBLICO QUE INTEGRAVA, À ÉPOCA DO FATO GERADOR DO DEVER DE INDENIZAR, A ESTRUTURA DO MINISTÉRIO DA SAÚDE - RESPONSABILIDADE CIVIL DA PESSOA ESTATAL QUE DECORRE, NA ESPÉCIE, DA INFLIÇÃO DE DANOS CAUSADA A PACIENTE EM RAZÃO DE PRESTAÇÃO DEFICIENTE DE ATIVIDADE MÉDICO-HOSPITALAR DESENVOLVIDA EM HOSPITAL PÚBLICO - LESÃO ESFINCTERIANA OBSTÉTRICA GRAVE - FATO DANOSO PARA A OFENDIDA RESULTANTE DE EPISIOTOMIA REALIZADA DURANTE O PARTO OMISSÃO DA EQUIPE DE PROFISSIONAIS DA SAÚDE, EM REFERIDO ESTABELECIMENTO HOSPITALAR, NO ACOMPANHAMENTO PÓS-CIRÚRGICO - DANOS MORAIS E MATERIAIS RECONHECIDOS - RESSARCIBILIDADE - DOUTRINA JURISPRUDÊNCIA - RECURSO DE AGRAVO IMPROVIDO. (SUPREMO TRIBUNAL FEDERAL, 2013, grifo nosso).

Importante esclarecer que de acordo com a Súmula 37 do Superior Tribunal de Justiça, é possível cumular as indenizações por dano material e dano moral oriundos do mesmo fato, como ocorreu na decisão supramencionada. 


\subsection{Do Dano Estético}

Por fim, segundo Tartuce apud Diniz (2018, p. 334) dano estético é toda alteração morfológica da vítima, abrangendo deformidades, marcas, defeitos, lesões gerando um motivo de exposição ao ridículo ou complexo de inferioridade, podendo ainda influenciar na capacidade laborativa. O ordenamento jurídico brasileiro não desconhece o aspecto moral do dano estético e vem buscando formas viáveis para a reparação, devido a unicidade de causa, mas a duplicidade de efeitos. Dessa forma, deve sempre o julgador analisar como seria o curso da vida cotidiana da vítima caso essa desfiguração estética não houvesse ocorrido.

Muito se discutiu sobre a possibilidade ou não de que fosse concedido indenização por dano moral e estético ao mesmo tempo. Gonçalves (2019) afirma que não se deve admitir a cumulação quando caracterizar bis in idem, e diante dessa discussão o Superior Tribunal de Justiça pacificou o entendimento através da Súmula 387: "É lícita a cumulação das indenizações de dano estético e dano moral".

Como já constatado, as formas físicas e sexuais podem gerar um dano estético a ser indenizado à vítima de violência obstétrica, vejamos a decisão a seguir:

Direito constitucional e administrativo. Responsabilidade civil do Estado. Erro médico. Juízo de origem que condenou o apelante a indenizar a apelada por danos moral e estético sofridos, fixando-os, respectivamente, em cem mil reais e trinta mil reais. Queimaduras de primeiro e segundo graus, decorrentes de bisturi elétrico, sofridas pela apelada durante o parto por cesariana. Laudo pericial que constata a existência de falha na prestação de serviço e o nexo de causalidade. Correta adoção de medidas no tratamento das queimaduras que não é capaz de eximir a responsabilidade da Administração Pública pela falha na prestação do serviço. Responsabilidade Civil Objetiva configurada. Art. 37, $\S 6^{\circ}$, da Constituição da República. Queimaduras que resultaram em uma cicatriz na região supra púbica. Apelada que era adolescente de dezesseis anos na data do parto. Danos estético e moral caracterizados. Precedente do STJ em caso semelhante. Redução dos valores arbitrados a título de indenização por danos estético, para vinte mil reais, e moral, para sessenta mil reais. Recurso parcialmente provido. (RIO DE JANEIRO, 2017, grifo nosso). 
Por estes aspectos, percebe-se o quão desumano as formas da violência obstétrica são, causando danos imensuráveis e que são amenizados pela indenização, mas jamais eliminados. Levando em consideração a quantidade de mulheres que sofrem essa violência no Brasil, se faz necessário que o Poder Público comece a tomar medidas para que esse comportamento na obstetrícia seja erradicado, adotando políticas públicas de humanização do parto, intensificando a fiscalização pelos Conselhos Regionais de Medicina, e principalmente ensinando os valores da humanização desde os primeiros ensinamentos da graduação.

\section{AS DIFICULDADES NO PROCEDIMENTO INDENIZATÓRIO}

Não há como afirmar que o processo indenizatório, diante da delicadeza desses casos, seja de fácil acesso ou desenvolvimento. A falta de informação sobre o assunto leva uma certa ignorância às vítimas, de modo que não se sabe como lidar com a situação, a quem recorrer ou quais providências tomar, principalmente diante da fragilidade que se encontram no momento pós parto e pós violência.

É latente em nosso ordenamento jurídico uma insegurança jurídica no que se refere ao processo indenizatório às vítimas de violência obstétrica. Isso porque na maioria dos partos em hospitais públicos o direito ao acompanhante é negado, sob o argumento de que a sala de parto é compartilhada por outras parturientes e a presença de um homem "desconhecido" pode ser constrangedor às outras mulheres que se encontram no ambiente.

O direito ao acompanhante foi garantido pela Lei no 11.108, de 7 de abril de 2005 e regulamentado pela Portaria ํㅡ 2.418, de 02 de dezembro de 2005. Desde então "ficam obrigados a permitir a presença, junto à parturiente, de 1 (um) acompanhante durante todo o período de trabalho de parto, parto e pós-parto imediato". (BRASIL, 2005). Entretanto, não estabelecem procedimentos para fiscalização e sanções administrativas em casos de descumprimento, comprometendo a eficácia e cumprimento efetivo da lei. Resta então, como reiterado em capítulos anteriores, a busca pelo judiciário para a busca pela tutela de seus direitos: 
RECURSO INOMINADO. AÇÃO DE INDENIZAÇÃO POR DANOS MORAIS. AUTOR QUE FOI IMPEDIDO DE ACOMPANHAR O PARTO DO SEU FILHO. PROCEDIMENTO DE EMERGÊNCIA. DANO MORAL NÃO CONFIGURADO. AUTORA QUE NÃO TEVE ASSEGURADO 0 DIREITO A ACOMPANHANTE DURANTE O PERÍODO DE PÓSPARTO IMEDIATO. VIOLAÇÃO À LEI № 11.108/2005. DANO MORAL CONFIGURADO. SENTENÇA REFORMADA. RECURSO CONHECIDO E PARCIALMENTE PROVIDO. (PARANÁ, 2014, grifo nosso).

Diante da negativa ao direito ao acompanhante é excluída a chance de possuir uma testemunha a seu favor, já que a parturiente está acompanhada somente da equipe médica, que são os agressores nessas situações. Analisando os casos, numa situação em que a paciente se encontra "sozinha" no momento de seu parto, é extremamente difícil obter provas de que foi xingada, ofendida, discriminada, e até abusada sexualmente.

$\mathrm{Na}$ esfera penal, os tribunais superiores vêm consolidando o entendimento de que nos crimes contra a liberdade sexual a palavra da vítima deve possuir grande valor no conjunto probatório. Isso se dá principalmente porque a grande maioria dos fatos ocorridos nesses crimes caracterizam violência de gênero. Então é necessário que a violência obstétrica passe a ser compreendida como violência de gênero e não como erro médico, e assim não sendo necessário a prova da culpa e sim o nexo causal, sendo o dano então presumido.

Inobstante a responsabilidade do estado ser objetiva, para a comprovação do nexo de causalidade, se faz necessário averiguar a conduta do médico porque a reponsabilidade médica é subjetiva, ou seja, com culpa comprovada. E a prova da culpa não é fácil de ser produzida, além dos motivos supracitados, porque nesses casos é exigido pelo juiz a prova pericial, por se tratar de matéria estritamente técnica, e essa prova pericial provavelmente será produzida por outro médico, que tende a isentar a culpa do colega de profissão. (CAVALIERI FILHO, 2020).

A menos que o dano seja extremamente grosseiro e gravoso, a vítima da violência obstétrica irá encontrar dificuldades no conjunto probatório. Destarte, não é razoável que a vítima tenha que sofrer danos graves e até correr risco de vida para que 
seu direito indenizatório seja assegurado sem dúvidas pelos tribunais. Veja, se a vítima não pode contar com a prova testemunhal, pericial, e sequer com a prova documental, visto que muitos prontuários são adulterados, acaba seguindo a busca por seus direitos a mercê de sua própria sorte ou clemência do julgador.

Através do Tema 983 o Superior Tribunal de Justiça firmou a tese de que nos casos de violência contra a mulher praticados no âmbito doméstico e familiar, é possível a fixação de valor mínimo indenizatório a título de dano moral. Sem dúvidas, é um avanço que o ordenamento jurídico brasileiro vem tomando no reconhecimento dos direitos das mulheres.

Ao analisar todos os aspectos que levaram este tribunal superior a firmar essa tese, não obsta crer que se resume às consequências que a violência de gênero pode causar na vida das mulheres após os episódios traumáticos. Dessa forma, leva-se a crer que a violência obstétrica deve ser entendida como violência de gênero, e isso ser levado em consideração sempre que houver necessidade de responsabilização civil dos agressores, presumindo-se o dano e assegurando a dignidade da parturiente.

\section{CONSIDERAÇÕES FINAIS}

O presente artigo possibilitou uma abordagem acerca da caracterização da violência obstétrica, da responsabilização civil do estado e dos agressores nos casos que ocorrerem em hospitais públicos, além dos danos indenizáveis possivelmente cabíveis nessas situações. Esse estudo se deu através de revisão bibliográfica e análise de julgados de tribunais estaduais e superiores, além de análise das legislações vigentes.

Foi possível perceber a negativa por parte dos julgadores em utilizar o termo "violência obstétrica" em suas ementas, o que acaba trazendo uma invisibilidade ao tema no curso processual desse fenômeno. Além disso, é possível perceber a caracterização dessas condutas como erro médico, o que segundo o estudado pode trazer dificuldades às vítimas ao produzirem provas em seu favor, já que assim se faz 
necessário demonstrar a culpa do agente público, além da produção de prova pericial por outro médico, que tende a proteger a categoria.

Nesse sentido, é de extrema importância que o sistema jurídico, em especial os magistrados, passe a analisar esses casos como violência de gênero, a fim de que se reconheça que os danos nesses casos são presumidos e não haja necessidade da demonstração de culpa, trazendo assim o mínimo de segurança jurídica sobre o assunto e a facilitação da reparação da honra e dignidade das vítimas.

Ademais, ainda há muito o que se investir em políticas públicas de prevenção para que se conscientize a sociedade em geral, os profissionais da saúde que lidam diretamente com essas situações e principalmente as vítimas que já sofreram essa violência para que busquem seus direitos, além das vítimas em potencial para que reconheçam essas condutas e tenham consciência da ilegalidade que possuem.

\section{REFERÊNCIAS}

AGUIAR, Janaina Marques de. Violência institucional em maternidades públicas: hostilidade ao invés de acolhimento como uma questão de gênero. 2010. Tese de Doutorado em Medicina Preventiva. Universidade de São Paulo. São Paulo, 2010. Disponível em: <https://www.teses.usp.br/teses/disponiveis/5/5137/tde-21062010175305/publico/JanainaMAguiar.pdf>. Acesso em: 11 abr. 2020.

BOERMA, Ties et al. Global epidemiology of use of and disparities in caesarean sections. Lancet, vol. 392, 2018. Disponível em: $<$ https://www.thelancet.com/journals/lancet/article/PIIS0140-6736(18)31928-7/fulltext>. Acesso em: 25 ago. 2020.

BRASIL. Constituição Federal de 1988. Promulgada em 5 de outubro de 1988. Disponível em: <http://www.planalto.gov.br/ccivil_03/Constituição/Constituição.htm> Acesso em: 17 mar. 2020.

. Lei $\mathrm{n}^{\circ}$ 10.406, de 10 de janeiro de 2002. Institui o Código Civil. Disponível em: <http://www.planalto.gov.br/ccivil_03/leis/2002/10406.htm>. Acesso em: 17 mar. 2020.

. Lei no 11.108, de 7 de abril de 2005. Altera a Lei $n^{0}$ 8.080, de 19 de setembro de 1990, para garantir às parturientes o direito à presença de acompanhante durante o trabalho de parto, parto e pós-parto imediato, no âmbito do Sistema Único de 
Saúde - SUS. Disponível em: < http://www.planalto.gov.br/ccivil_03/_ato20042006/2005/lei/l11108.htm>. Acesso em: 09 set. 2020.

. Superior Tribunal de Justiça. Recurso Especial: 1089955-RJ 2008/02054644, 1a Turma, Relatora: Denise Arruda, 03 de novembro de 2009. Disponível em: <https://stj.jusbrasil.com.br/jurisprudencia/6165906/recurso-especial-resp-1089955-rj2008-0205464-4/inteiro-teor-12302690>. Acesso em: 21 abr. 2020.

. Supremo Tribunal Federal. Agravo Regimental em Agravo De Instrumento 852237-RS, Relator: Min. Celso de Mello, 25 junho de 2013. Disponível em: $<$ https://stf.jusbrasil.com.br/jurisprudencia/24806123/agreg-no-agravo-de-instrumentoai-852237-rs-stf/inteiro-teor-112279928?ref=juris-tabs>. Acesso em: 25 abr. 2020.

. Supremo Tribunal Federal. Recurso Extraordinário: 1027633-SP. Relator: Marco Aurélio, 14 de agosto de 2019. Disponível em: <http://www.stf.jus.br/portal/jurisprudencia/listarJurisprudencia.asp?s1=\%28RE\%24\%2E $\mathrm{SCLA} \% 2 \mathrm{E}+\mathrm{E}+1027633 \% 2 \mathrm{ENUME} \% 2 \mathrm{E} \% 29+\mathrm{OU}+\% 28 \mathrm{RE} \% 2 \mathrm{EACMS} \% 2 \mathrm{E}+\mathrm{ADJ} 2+1027$ 633\%2EACMS\%2E\%29\&base=baseAcordaos\&url=http://tinyurl.com/y52gvkfg>. Acesso em: 21 abr. 2020.

Tribunal de Justiça do Distrito Federal. Apelação Cível no. 001978622.2004.8.07.0001. Relator: Alfeu Machado, 29 de janeiro de 2014. Disponível em: $<$ https://tj-df.jusbrasil.com.br/jurisprudencia/116350814/apelacao-civel-apc20040111065442-df-0019786-2220048070001 >. Acesso em: 21 abr. 2020.

. Tribunal de Justiça do Paraná. 1a Turma Recursal. Recurso Inominado no 0003708-71.2014.8.16.0026. Relatora: Renata Ribeiro Bau, 12 de maio de 2015. Disponível <https://portal.tjpr.jus.br/jurisprudencia/j/2100000001946511/Ac\%C3\%B3rd\%C3\%A3o0003708-71.2014.8.16.0026\#>. Acesso em: 09 set. 2020.

. Tribunal de Justiça do Rio de Janeiro. Apelação Cível e Reexame Necessário no 0296134-49.2013.8.19.0001. Relator: Alexandre Freitas Câmara, 22 de fevereiro de 2017.2 Disponível em: <http://www1.tjrj.jus.br/gedcacheweb/default.aspx?UZIP=1\&GEDID=00043C1D49CBD9 F04B7F978C466643B664FFC5060A570F5D>. Acesso em 25 abr. 2020.

. Tribunal de Justiça do Rio Grande do Sul. Apelação Cível n .70059123844. Relator: Jorge Alberto Schreiner Pestana, 29 de maio de 2014. Disponível em: <https://tj-rs.jusbrasil.com.br/jurisprudencia/126515070/apelacao-civel-ac-70059123844rs/inteiro-teor-126515080>. Acesso em: 21 abr. 2020.

. Tribunal de Justiça de São Paulo. Apelação no 0001314-07.2015.8.26.0082. Relator: Fábio Podestá, 11 de outubro de 2017. Disponível em: <https://tj- 
sp.jusbrasil.com.br/jurisprudencia/509315821/13140720158260082-sp-00013140720158260082>. Acesso em: 25 abr. 2020.

CAVALIERI FILHO, Sergio. Programa de responsabilidade civil. 14. ed. São Paulo: Atlas, 2020.

GAGLIANO, Pablo Stolze. FILHO, Rodolfo Pamplona. Novo curso de direito civil, v. 3: responsabilidade civil. 17. ed. São Paulo: Saraiva Educação, 2019.

GONÇALVES, Carlos Roberto. Direito civil brasileiro, volume 4: responsabilidade civil. 14. ed. São Paulo: Saraiva Educação, 2019.

MAZZA, Alexandre. Manual de Direito Administrativo. 9. ed. São Paulo: Saraiva Educação, 2019.

PARTO DO PRINCÍPIO. "Parirás com dor": Dossiê elaborado pela Rede Parto do Princípio para a CPMI da Violência Contra as Mulheres. Disponível em: <https://www.senado.gov.br/comissoes/documentos/SSCEPI/DOC\%20VCM\%20367.pdf >. Acesso em: 11 abr. 2020.

SILVA, Artenira da Silva e; SERRA, Maiane Cibele de Mesquita. Violência obstétrica no Brasil: um enfoque a partir dos acórdãos do STF e STJ. Quaestio luris, vol. 10, nº. 04, Rio de Janeiro, 2017. p. 2430-2457. Disponível em: <https://www.epublicacoes.uerj.br/index.php/quaestioiuris/article/view/28458/21893>. Acesso em: 11 abr. 2020.

TARTUCE, Flávio. Manual de responsabilidade civil: volume único. Rio de Janeiro: Forense; São Paulo: Método, 2018.

TOCANTINS. Lei $\mathbf{n} \mathbf{3}$ 3.385, de 27 de julho de 2018. Dispõe sobre a implementação de medidas de informação e proteção à gestante e parturiente contra a violência obstétrica no Estado do Tocantins. Disponível em: <https://www.legisweb.com.br/legislacao/?id=365587> . Acesso em: 29 ago. 2020.

VENTURI, Gustavo.; BOKANY, Vilma.; DIAS, Rita. Mulheres brasileiras e gênero nos espaços público e privado. São Paulo: Fundação Perseu Abramo/Sesc, 2010. Disponível em: <http://csbh.fpabramo.org.br/sites/default/files/pesquisaintegra.pdf>. Acesso em: 11 abr. 2020. 